\title{
Dental Health Personnel Planning: a Review of the Literature
}

\author{
Harold S. Goodman, DDS, MPH \\ University of Michigan \\ Program in Dental Public Health \\ Ann Arbor, MI \\ Robert J. Weyant, DMD, MPH \\ Department of Veterans Affairs \\ Great Lakes Regional Health Services Research and Development Field Program \\ Ann Arbor, MI
}

\begin{abstract}
Dental personnel planning is important in formulating policy in dental education, dental public health programs, and dental care delivery systems. The purpose of this literature review is to illustrate the use of dentist-topopulation ratios, need-based models, and demandbased models in the determination of appropriate supply of dental personnel. A historical perspective is provided that demonstrates how political manipulation and subjectivity have characterized the use of these models by organized dentistry, the federal government, and others. The lack of pertinent data and the inability to predict economic, social, political, and epidemiologic trends weaken the applicability of each model in determining future personnel levels. Considering the long-term consequences of the use of each model in personnel planning, caution is urged in using any of the presently available models.
\end{abstract}

Key Words: manpower, econometrics, dentist-to-population ratio, need, demand, forecasting.

Health personnel planning (the gender-neutral term "personnel" is preferred over the more common "manpower") is the process whereby a determination is made regarding the appropriate numbers, types, and distribution of individuals capable of providing health services to achieve a desired goal or health outcome (1). The determination of necessary personnel levels is based on the relation between the variables of consumer's need or demand and the availability or supply of dental care. Their interaction defines the ultimate utilization of dental services and, to some degree, the health status of the population. Personnel planning relates these variables in a manner that, ideally, permits accurate prediction of

Send correspondence to Dr. Weyant, 1609 Barrington, Ann Arbor, MI 48103. Manuscript received: $2 / 13 / 89$; returned to authors for revision: $5 / 2 / 89$; accepted for publication: $6 / 27 / 89$. future personnel requirements. These predictions may then be used to initiate modifications in the personnel pool so that appropriate numbers, types, and distributions of dental providers result. The production of dental services is strongly influenced by the availability of personnel, because the provision of dental services is labor intensive. This dependence on personnel supply, coupled with the long training time required for dentists, means that required changes in future personnel levels need to be anticipated years in advance. Thus the reliability of any personnel planning model will be strongly influenced by its ability to estimate future need and demand levels.

The need to plan for dental health personnel is rooted in the ethical imperative to use limited health resources appropriately. A central problem though, is deciding from whose perspective the decision of appropriateness should be made. The determination of appropriateness is based on subjective values held by each potential evaluator of personnel need. The list of evaluators includes consumers, providers, purchasers of dental care, and private and public policy makers (2). Frequently the perspectives of these groups differ, as well as their ability to influence the subsequent production and distribution of dentists. For example, the government's role in dental health personnel planning is, in part, to ensure that adequate care is received by consumers in an efficient manner. The federal government may manifest this role through antitrust legislation and elimination of advertising bans in an attempt to foster competition and market regulation of price (3). On the other hand, organized dentistry in the United States has generally been concerned with ensuring the economic well-being of its constituents through advancing the "free enterprise" fee-forservice system (4). Given the economic realities of the dental marketplace, this concern may take the form of attempts to curb competition for dental care dollars either by discouraging the production of new dentists or by preventing the shift of care provision to nondentist providers. The promulgation of the notion of a growing 
oversupply of dentists by the American Dental Association (ADA) is a natural outgrowth of this concern.

This widely held notion that there is and will continue to be an oversupply of dentists has fueled the lobbying efforts of organized dentistry to reduce the supply (5). This notion, along with federal initiatives to cut health care spending, may soon result in a crisis in access to dental care for many. Even if one acknowledges the decline in dental caries prevalence in the United States, there still remain many individuals who experience serious dental problems (6-8). In addition, there are growing groups of potential consumers-including poor, rural, elderly, homebound, institutionalized, and HIV-infected individuals - whose access to dental care is limited $(9,10)$.

Personnel planning models serve at least ostensibly as the basis for predicting future personnel needs. Many important personnel decisions are being made that will have long-term effects on dental care in the United States. Therefore, the validity and reliability of personnel planning models with respect to their ability to predict needed supply levels should now be revisited. This examination may be especially timely in that many of the assumptions upon which the models are based have changed in recent years.

This article will review the literature to investigate how personnel planning models have developed and are used. A historical overview of the last 100 years will be given to help illustrate the subjective and inherently political nature of dental health personnel planning. Consideration will be given to the elements of need and demand, including econometric models, in predicting dental personnel supply. Such models will be reviewed with respect to dental personnel distribution, special populations, and the current crisis in support for public dental programs.

\section{Definitions}

Any discussion of dental personnel should start with a review of frequently used and often confused terms. Demand derives from a desire and attempt by the public to seek dental care (11). Striffler defines desire plus the ability to obtain dental service as effective demand (12). In contrast, potential demand refers only to the desire for care, but without its attainment. The most commonly used measure of effective demand by economists has been the variably defined utilization of dental services (13-16).

Feldstein calls the supply of dental care the "stock of dentists" (17). It is perhaps more useful to consider the supply of dental care as the entire productive capacity of the dental care system. This productive capacity derives from the types of personnel (e.g., dentists, hygienists, assistants) available to deliver dental care, the technologies used, the care methods employed, and the time spent in the provision of care. Need is most commonly considered as the professionally determined require- ment for care (12). Spencer defines need as "that quantity of dental health care which expert opinion judges ought to be consumed over a relevant time period" (11). This is also termed normative need. On an individual basis, need is the result of diagnosis and treatment planning by the dentist.

In classic economic modeling, the supply and demand for care are related to each other through changes in price or in such nonmonetary-cost items as the waiting time required for service. The dental care system, however, rarely behaves in the manner described by common economic models $(12,18)$. In fact, the relation of need and demand is a variable function of many social, psychological, economic, and biological factors, most of which defy current descriptions in economic terms (19). Given the reality of the marketplace, only the amount of care that is demanded in a given population will actually be "consumed." Furthermore, this effective demand for dental care rarely equates with professionally determined need in a population. This inability to align need correctly with demand underlies one major difficulty in planning for personnel production and distribution. The entire personnel planning process is based on assumptions and values, rendering it vulnerable to the political process. The confusion is further enhanced by the constant change in need, demand, and supply resulting from medical, technological, social, economic, and political trends, most of which are difficult to predict.

The production of dental services is strongly influenced by the availability of personnel, because the provision of dental services is labor intensive. This dependence on personnel supply, coupled with the long training time required for dentists, means that required changes in future personnel levels need to be anticipated years in advance."

The three most commonly used ways to develop models of dental personnel are: dentist-to-population ratios, demand-based models, and need-based models. The ultimate choice of a model is based on either the availability of data to support the model or on the political or philosophical basis of those doing the evaluation. A description of each model is discussed in the following sections. The first model considered is the commonly used and easily understood dentist-to-population ratio. Second is the demand-based model and its elaborate relative, the econometric model. A consideration of needbased models then follows.

\section{Dentist-to-Population Ratio}

Derivation. The dentist-to-population ratio simply counts the number of dentists present within a specific 
population and has served as a traditional measure of the need for dental personnel (20-26). When this ratio is compared with an "accepted" ratio, it provides the basis for determining whether a shortage or oversupply of dental providers exists. It is viewed by its advocates as a simple supply-to-demand ratio, with the number of dentists serving as the supply and the total population serving as the demand. This ratio has served as the basis for numerous health personnel planning initiatives by the federal and state governments in the United States, as well as by the ADA and its components $(2,27-32)$. The US is not alone in estimating personnel needs by use of a ratio technique. Willcocks and Richards provided listings of dentist-to-population ratios in over 20 widely varying nations (33).

The reliance upon the dentist-to-population ratio is not hard to understand. The necessary information appears relatively easy to obtain when compared to most other techniques, and the required calculations are straightforward. The modeling process begins with estimates of the current ratio based on census data and estimates of the number of (practicing clinical) dentists. Sources such as state licensing agencies, direct surveys, or the ADA are frequently used to determine the dental supply. The dynamics of the system are then modeled according to estimates of changes in both the population and numbers of dentists. Factors such as the number of students in dental schools and the in-migration pattern of foreign dentists work to increase the available supply of personnel. Factors working to reduce the supply of dentists include mortality, retirement, and out-migration.

Once relative rates are assigned to each factor, estimates of the number of dentists can be made for any point in the future. These estimates are then compared to predicted population levels. If some particular ratio of dentists-to-population other than the predicted one is desired, then policies must be initiated that will affect the dynamics of the dental supply. This technique was employed on a national basis by House and coworkers in an attempt to develop a model of the Canadian system (34).

In the past, the ADA and the federal government have based projections of need for future supplies of dentists on projected changes in the dentist-to-population ratio $(35,36)$. As late as 1962 , the ADA had determined the dentist-to-population ratio to be the best single measure of the adequacy of dental services, the comparison of geographic areas, and the determination of trends over time (37). The ADA had acknowledged, however, that "no ideal or proper ratio can be established" because of variations in disease levels, economic factors, and dentist's productivity (37). ADA policy has now changed, and the dentist-to-population ratio has been declared unsuitable for evaluating personnel requirements (38).

Historical Background. In 1850, the United States
Bureau of the Census counted 2,900 dentists for a population of 23 million, giving a ratio of one dentist to 8,000 population (39). This was the first official count of the number of dentists in the US. This ratio increased steadily until it peaked in the 1930s with a ratio of one dentist for every 1,728 persons. The closing of the proprietary schools in the wake of the Geis report curtailed the supply of dentists, and the ratio of dentists to population decreased until the early 1970 s $(40,41)$.

One of the first studies to base future estimates of health personnel upon the health service needs of the population was conducted by Lee and Jones in 1933 (42). It would be another 20 years, though, before legislation was enacted to affect the supply of dentists (43). The President's Commission on the Health Needs of the Nation in 1953 devised an early dental supply-and-demand projection for 1960 based on the maintenance of a 1952-53 dentist-to-population ratio. Based on personnel data from the Public Health Service and the ADA, and population projections from the Bureau of the Census, demand was anticipated to outgrow anticipated supply throughout the remainder of the 1950 s $(23,26)$.

In 1959, the Bane Committee concluded that there was a maldistribution of dentists, and provided recommendations for supply allocations to alleviate the perceived shortage (20). Dentist-to-population ratios were again used, but demand variables such as income, age composition, educational level, and the degree of urbanization were also included in the model. That same year, Moen, an economist with the ADA, determined that the dental office was keeping pace with increased demand by increasing productivity and challenged the necessity of maintaining the current dentist-to-population ratio (44). Although the American Council on Education's "Survey of Dentistry in the United States" in 1961 recognized the impact upon demand of fluoridation, auxiliary personnel utilization, and technical advances such as the air turbine, these factors were still not considered in determining future need for dentists (45).

At a University of Michigan workshop in 1962 concerning dental personnel, Moen recommended that population growth, dentist productivity, and demand for dental care be the key elements considered in dental personnel projections (46). Other than accepting the need to increase the utilization of dental auxiliaries, the conference failed to incorporate most of Moen's recommendations. During a period of growth in the economy and education levels of the population, it was expected that demand for dental services would continually outstrip dentist supply. Indeed, the percent of individuals making a dental visit within two years did increase steadily during the 1950s and 1960s (47). Recommendations for the expansion of dental school enrollment and expanded auxiliary utilization were therefore accepted by the conference as a way to maintain the dentist-topopulation ratio and to balance supply with demand 
(46).

In 1963 the American Dental Association used the dentist-to-population ratio to lobby for legislative support for the Health Professions Education Assistance Act (Public Law 88-129) (48). This act was designed to counteract the perceived shortage of dentists through a series of measures geared to increase the number of dental graduates (48-50). In testimony before Congress, representatives of the ADA estimated a shortfall of 12,000 dentists by 1975 if drastic measures were not enacted to increase the supply. The Bane Commission gave similar estimates in support of the same legislation (20). Their estimate stated that, given present production rates, a supply of 118,000 dentists would be in practice in 1975, when there would exist a need for 134,000 dentists.

\section{"The dentist-to-population ratio simply counts the number of dentists present within a specific population and has served as a traditional measure of the need for dental personnel."}

Interestingly, Feldstein offered an al ternative analysis of this same situation (51). Finding discrepancies in the data reported by the ADA, he recalculated the projections based on data published by the ADA. These data differed from the data which were supplied as testimony for federal aid for dental training. By calculating the dental visit per population rate for 1958 and 1962 with the rate projected (in 1962) for 1975, Feldstein found that the projected supply of dentists through 1975 (in the absence of federal intervention) would have been sufficient to supply the same rate of visits per persons as was available in 1961 (51).

In 1965, the ADA again published forecasts of the number of dental school graduates needed for the 1963 dentist-to-population ratio to be maintained through 1985 (36). Attention centered upon dental school enrollments and estimated dentist mortality. There was no apparent concern for changes over time in dental demand and productivity. The dentist-to-population ratio continued to be used, however, due to its ease in utilization and understanding.

During the economic prosperity of the 1960s that facilitated enactment of the federal "Great Society" legislation, the Health Professions Educational Assistance Amendment of 1965 (Public Law 89-290) and the Allied Health Professions Personnel Act of 1966 (Public Law 89-751) were signed into law. Provisions for the cancellation of loans to health professions students were offered if they practiced in a shortage area designated by a dentist-to-population ratio of 1:3,000 $(49,52,53)$. The Health Manpower Training Act of 1971 (Public Law 92-157) provided continued financial support to health profes- sional schools, but with stricter fiscal provisions $(54,55)$. The dentist-to-population ratio still remained the basis for the federal subsidization of dental schools and the implementation of programs such as Expanded Function Dental Auxiliaries (EFDA) in order to respond to the predicted personnel shortage.

Beginning in the 1970s, however, the ADA seemed to offer only cautious support for government dental health programs (56). This decline in support possibly reflected a change in the ADA's perception regarding the supply level of dentists. In 1971, as the perception of an oversupply of dentists was beginning to form, the Emergency Health Personnel Act (Public Law 91-623) was enacted to establish the National Health Service Corps to provide care to critical health personnel shortage areas. Similar to most federal health programs, this initiative was designed primarily with physicians in mind (57-59). Nevertheless, a dentist-to-population ratio of 1:5,000 was eventually set by the federal government to identify dental personnel shortage areas (27). Disagreement regarding designation of a dental shortage area erupted at the local level between organized dentistry and the federal government (60). This rift has been attributed to the inherent insensitivity of the dentist-to-population ratio to measure accurately the supply of dental services (50).

A change in trends was manifest in the 1970 s that reflected the interaction of unpredicted social, political, and economic transformation that continually seemed to confound personnel forecasting. Fueled by a dramatic decrease in the rate of population growth, a sluggish economy, and increasing numbers of dental graduates, organized dentistry feared that the profession would be increasingly vulnerable to governmental control and regulation (61). Regarding federal influence on dental education, the ADA Council on Dental Education stated that: " ... it is becoming increasingly more apparent that the US Office of Education is exerting greater control of nongovernmental accreditation. The profession must support the concept of nongovernmental voluntary accreditation and oppose the development of federal accreditation programs in the United States (61)." The statement also proceeded to approve of nonfederal control over the financial support of dental education (61). In fact, although the ADA had strongly supported the various legislative educational acts that were designed to alleviate the predicted shortage of dentists, the government was nevertheless implicated for the alleged oversupply $(62,63)$.

By 1976, the ADA's House of Delegates had enacted various policy revisions that reflected their belief that a shortage of dental personnel no longer existed. Perhaps in fear of the competitive economic pressures wrought by the oversupply perception, the utilization of expanded function dental auxiliaries (EFDA) was discouraged through policy statements of the ADA $(64,65)$. One such statement was to rescind a 1960 policy that 
called for an increase in training dentists and dental auxiliaries in dental schools $(64,66)$. What had in many minds now become an oversupply, however, was still defined within the limited reference of a dentist-topopulation ratio.

Changes were enacted into the Health Professions Educational Assistance Act (Public Law 94-484) when it was renewed in 1976 in an effort to improve the means of identifying shortage areas (27,61). The "Designation of Health Manpower Shortage Areas" (Section 332) was added to the Public Health Service Act $(27,67)$. This section established new criteria such as designating urban shortage areas and broadening the concept of shortage beyond the dentist-to-population ratio to consider population need for health services. The 1976 Health Professions Assistance Act also placed emphasis on improving the number of primary care personnel by requiring dental schools to meet certain criteria if they were to request and qualify for federal support funds. Such criteria included increased first-year enrollment dependent on class size, and the training of students in areas remote from the teaching site $(27,67)$. Organized dentistry viewed this act as a further governmental threat to its autonomy $(62,63)$. This perceived interference extended to the dental educational domain as well when six dental schools refused to request the federal support allocated by this act (68).

In 1980, criteria for designation of a shortage of personnel supply were more categorically defined by regulation (69). Key elements of the regulation included identifying a shortage area by a 1:5,000 dentist-to-population ratio or greater than 1:4,000 if in "critical" health and/or dental personnel need, as well as an increased assessment of the personnel situation in "contiguous" areas (69).

Disadvantages. Many authors have highlighted the shortcomings of the provider-to-population ratio $(30,51,70)$. One of the underlying assumptions is an anachronistic belief in the ubiquitous nature of dental disease. This assumption results in a perception of both universal need and in a determinable and consistent demand for care, even among widely different populations over time (30). Unfortunately, given the actual difficulty in obtaining reliable data to describe the practice of dentists and to estimate need and demand among groups, this assumption is frequently invalid. As a result, the predictive value of this technique has been questioned (71).

A source of data on the supply of dental personnel is critical to good estimates with this model, but hard to obtain. The ADA initiated a series of published reports in the 1940s on the number and distribution of dentists in the US. The American Dental Directory and the Distribution of Dentists in the United States are published annually; the Survey of Dental Practice, every three years. These ADA publications, as well as the Bureau of Census data, still provide the best sources of information on the overall number of dentists in this country. These documents and state licensing rosters contain little information concerning the personal and production characteristics of individual providers.

On the supply side, real changes in the productivity potential of dentists are ongoing $(51,66,72)$. Ratio techniques fail to account for differences in provider productivity, however. Furthermore, the shifting of some dental care procedures to nondentist personnel is not detected by this approach. Interestingly, as far back as 1959, the ADA commented that while demand for services would increase, increased use of auxiliaries would not be a viable way to change the productive capacity of the dental care system (35). It was argued that dentists' "temperament" and a lack of busyness in certain urban practices would work to prevent the use of additional auxiliary personnel.

\section{"From a public health standpoint, a health-needs approach to estimating personnel may be preferable to other techniques because it identifies not only disease levels, but also permits treatment to be prioritized and allows evaluators to track movement toward health objectives."}

Factors that affect the demand for dental care are also not well accounted for in the dentist-to-population ratio. Changes in financing mechanisms have been shown to alter (although not drastically) the demand for service $(9,19,73-75)$. Furthermore, technological changes (e.g., porcelain veneering, dental implants, sealants) may rapidly create changes in demand levels. Other variables that have been shown to have an effect on demand, such as sex, age, disease level, and socioeconomic status, are ignored by the dentist-to-population ratio $(30,31,76)$. When one compares different populations using ratio techniques, the lack of consideration of certain variables known to influence demand may lead to poor results.

Since ratios also ignore the dentists' specialty mix, matching the range of available services with either need or demand is not possible (77). Meskin observed that the use of ratios was more effective when dental disease was more widespread and dental care was generally provided in a private practice setting by an overwhelming majority of solo general practitioners (30). As need within population subgroups varies dramatically and alternatives to fee-for-service solo practices become more common, these ratios lose validity as adequate measures of personnel needs.

Another shortcoming is the implication that, through the establishment of an "acceptable" ratio, some ideal level exists. The derivation of the dentist-to-population ratio, however, is quite arbitrary (29). For example, the 
setting of a politically determined county and/or state border as a parameter when using a ratio can be a poor personnel forecasting tool in designating shortage areas. Dramatic changes in the dentist-to-population ratio occur with hypothetical change of a boundary line or by the exclusion of one community within the area (29).

Odrich doubts whether such a ratio can evaluate either need or demand (14). Instead of evaluating need, the ratio measures the population size that can meet the needs of the dentist and is incapable of measuring the needs of the population above that level. In addition, Born notes that ratios omit the demand-dependent notion of price (28). Dentist-to-population ratios when used alone are insensitive to the complexities involved in assessing the need and demand for health personnel.

Outcome. The 1986 dentist-to-population estimate for the United States was a ratio of one active civilian dentist per 1,745 people (78). Similar estimates have been used by the ADA to substantiate its request for a decrease in the production of dental professionals $(79,80)$. While recently acknowledging that "modestly" declining dental school enrollments will eventually contribute to a future decrease in the supply of dentists, the ADA maintains that the oversupply of dentists will continue

\section{"As late as 1962, the ADA had determined the dentist-to-population ratio to be the best single measure of the adequacy of dental services, the comparison of geographic areas, and the determination of trends over time."}

throughout the remainder of the century (80). This differs with the American Association of Dental Schools' assessment that a rather dramatic decline in enrollment will cause the number of dentists to "decline" by the mid1990s (81,82).This ADA concern for an oversupply is heightened by secular changes in disease levels causing a perceived shortage of need and demand, the so-called busyness problem. This has resulted in state practice acts becoming more restrictive regarding the use of dental auxiliaries despite the documented productive capability and efficiency of auxiliaries in both the public and private sphere (83). In 1987, the ADA also rescinded a 1966 policy that urged individual practitioners to meet increasing demand with expanded use of auxiliaries (84).

Private practitioners have warned that if demand does not increase soon, falling incomes and diminishing economic incentives will cause the quality of the dental product to suffer (85). In sharp contrast to this proposition, the average income of dentists rose from $\$ 57,510$ in 1981 to $\$ 76,050$ in 1986 , outpacing an increase in inflation by 11.6 percent (86). The dental component of the con- sumer price index increased at about twice the rate of the overall index during the same period (78). It therefore seems odd that, within an alleged oversupply situation, both real income for dentists and prices for dental services would have increased to such an extent. Economic theory says otherwise. Therefore, there is either overtreatment or overpricing or both, or there is enough consumer demand to meet the present supply of dentists. The behavior of dental costs in the face of changing demand is explained by the "target income hypotheses" of provider-induced dental demand (87). If, as proposed, the dental care market does not act as a perfect economic entity, one must question the criteria used by organized dentistry to determine and proclaim an oversupply of dentists. It can be argued that a population can absorb any supply of dental services, for it is the dentists who will be the major determiners of demand.

Unfortunately, the pressure to reduce the number of dentists to maintain these income and price levels promulgates the perception of a lack of dental need or disease in the population. Accordingly, public dental programs may not be funded due to the perception that there are an abundant number of dentists to take care of what little disease is remaining. Striffler commented editorially (88):

The impact of the perceived oversupply of dental personnel on dental public health may be ... felt in the area of care of special population groups-the poor, the aged, and the otherwise disadvantaged, to mention a few. One suspects that private practitioners who only a few years ago were happy to see organized public health programs reach out to provide care to these special groups are now dragging their feet when asked to support the continuance of the programs either in principle or at the legislature.

This perception has contributed to caution and fiscal restraint within federal and state governments and educational institutions regarding dental public health programs and dental education. The results have been rather dramatic: the federal Division of Dentistry has been virtually eliminated and there has been a loss of dental public health programs at both the state and local levels (89). Funding has decreased or ceased for student tuition, construction and maintenance grants, and National Health Service Corps scholarships $(29,73,90)$. There has been a 35 percent decrease in first-year dental school enrollment over the last decade, as well as a 69 percent decline in the number of applicants since 1975 $(82,84)$. This decline has contributed, in part, to the imminent closure of four dental schools. The pace of this activity has been hastened recently by a federal budget deficit incurred within a politically conservative administration. These austere policy ramifications, in part, stress the critical need for a more reliable tool in personnel forecasting. 


\section{Demand-based Studies}

Demand-based approaches are directed toward recognizing and measuring market forces that are thought to be important in generating the demand and supply of dental services. Estimates of dental personnel requirements are based on current levels of utilization of dental services, as well as current behavior patterns of consumers within the dental health marketplace (2). One advantage of this model is that it attempts to identify and quantify market forces that affect consumers and suppliers. The use of economic variables also allows the model to measure the response of current users to changes in the delivery and financing of dental services. The model seems to have its greatest applicability in the fee-for-service health care system found in the United States, a system in which its advocates affirm the role of supply and demand as the basis for the provision of services. This supply and demand relation is used in econometric models by government on a national and state level in the United States, and by the ADA to forecast dental personnel requirements (2).

Economic Theory and Econometric Modeling. Economic theory holds that the supply of dental services is a function of the price. McDermott considers price to be the key determinant of demand for a market of dental services that is controlled by the law of supply and demand (91). Should personnel planning then be demand-based? If a price-sensitive or elastic dental market is capable of regulating the supply of dentists, then public demand will effectively determine the supply. Thus there must be an economic incentive for someone to choose to enter the profession. Then, once practicing, economic incentives will determine the amount of time that a dentist will devote to clinical care.

Economists have attempted the difficult process of modeling the dental marketplace to forecast needed levels of dental personnel. Reinhardt provides an economist's perspective when he says (92):

It is always effective demand and not perceived need that interacts with the effective supply to determine the actual utilization of services and of health manpower. For that reason economists generally prefer to develop their forecasts on the basis of effective demand and not need, even at the risk of being accused of insensitivity to human needs. It is simply a question of realism.

One of the first economists to address the various determinants of the dental marketplace was Maurizi who, in 1969, focused on measures of productivity (93). Cole and Cohen in 1971 evaluated probable demand levels by examining technological advances, auxiliary utilization, and practice organization, as well as factors of income and education (15). The dental manpower subcommittee of the ADA's 1971 Task Force also incorporated a range of attributes that were translated into personnel requirements. This report used the number of patient visits as an indicator of both supply and demand (94).

Cole and Cohen estimated the supply of dental services by use of a dollar value scale, based on ADA surveys $(15)$. These were balanced against demand estimates based on dental visit rates. In this case, the unmet demand was measured by proxy variables such as age and educational levels in the population. The legitimacy of this approach has not been established since fees may not always be set in a uniform fashion nor are dental visits uniform. Beck and McGill estimated the supply of dental services by calculating dynamic changes in the dentist population (95). They subsequently factor in productivity values from data provided by the ADA's Survey of Dental Practice and relate these results to demand measured in per capita dental visits.

Demand studies provide a refinement to dentist-topopulation ratio estimates. By applying economic principles, demand-based approaches attempt to identify additional factors that may be important in understanding personnel needs. The ADA Dental Planning Information System (DPIS) was developed over a period of years in the mid-1970s in an attempt to determine personnel needs (96). The DPIS used rather intricate equations to incorporate factors such as dentist productivity, dental service utilization, and the present and projected number of dentists in its calculations. The reliance of the DPIS on possibly biased information gathered by various state health agencies and dentists fesiding in these states diminished its objectivity and effectiveness in formulating personnel predictions. Scant attention has been paid to the DPIS in recent years.

The Department of Health, Education, and Welfare (DHEW) in 1977 also considered additional personnel factors in its "Projections for National Requirements for Dentists: 1980, 1985 and 1990" (97). This report attempted to project the number of dentists needed so that the costs of dental services do not increase at a rate higher than the cost of other goods and services. This projection was to be accomplished by balancing the supply of dental services with the estimated demand for dental services (97). These projections used future estimates of the population, economy, and dental insurance utilization to estimate future demand.

In 1979, the Bureau of Health Manpower of DHHS added further sophistication to this process when issuing a report entitled "Forecasts of Employment in the Dental Sector to 1995" (98). Forecasts of dental economic variables were produced in place of projections by using an econometric model of the dental sector that was formulated in 1973 by Feldstein and others $(17,51)$.

Forecasts differ from projections in that forecasts predict changes on the basis of a known causal relation, whereas projections generally assume that present trends will continue (99). Econometric models of the dental sector analyze productivity as a measure of the 
many supply and demand variables that are ignored in the dentist-to-population ratio. For a forecast to be generated, specific inputs are furnished from independent data sources $(51,78)$. These include determinations of the gross national product, economic dental demand, population growth, real per capita income, and the number of dental graduates (78). The model then provides a range of alternatives based on how much variation exists within each assumption. The resultant output of these models can cover a wide range of possibilities.

The resulting model presumably can predict dental care spending, price, utilization, dentist's income, use of auxiliaries, and personnel supply. The value of the model is in identifying determinants of demand in the marketplace, thereby permitting estimates of future demand. Elasticity (price sensitivity) is one such determinant and is an important component of the econometric model. Focusing upon the price elasticity of demand allows the model to demonstrate the effect of changes in price on utilization, as well as the effect of changes in auxiliary use on dental care. By understanding the costs associated with each determinant, the more cost-effective strategies for increasing demand can be tested. Hirsch and Killingsworth in 1975 took the econometric model of the dental sector one step further (100). In addition to the market dynamic variables of supply and demand, their model incorporates elements of sociology, psychology, and epidemiology. This miodel may have the potential of providing a more realistic description of the dental care system.

Although restricted by insufficient data, these complex models attempt to use an index other than the dentist-topopulation ratio to forecast required personnel supply. Econometric models also add a level of sophistication by examining the effects of change on supply, demand, and price.

Disadvantages. Several recurring problems seem to run through most economic theories of health care when used to predict demand. First of all, utilization as a measure of demand fails to consider either the amount or type of treatment rendered. Striffler cautions that "utilization" and "demand" are concepts that should not be used interchangeably (12). Utilization is commonly measured by economists by the number of visits per patient per year, whereas demand refers to the quantity and type of services purchased at a given price. If measured by such a criterion, utilization does not determine the number of individuals using the service, the quantity and type of services purchased, nor the dentists' time consumed (12).

This relation also implies that if people are receiving and using services, they are effectively demanding care. The degree of utilization is different for the individual who visits the dental office every six months in contrast to the person who only used the service on an emergency basis $(13,18)$. Yet, in response to a question concerning whether a dental visit had occurred over the past 12 months, utilization for both individuals would be the same.

There are also problems in using the dental visit as a dependent variable in measuring demand because it does not distinguish between a patient and a dentist-initiated visit (18). Does it constitute patient demand for services when the dentist initiates the followup or recall visit? For several reasons, total dental visits frequently breaks down as an assessment of demand.

\section{"By 1976, the ADA's House of Delegates had enacted various policy revisions that reflected their belief that a shortage of dental personnel no longer existed. Perhaps in fear of the competitive economic pressures wrought by the oversupply perception, the utilization of expanded function dental auxiliaries (EFDA) was discouraged through policy statements of the ADA.}

Perhaps a more significant problem regarding a demand-based approach is that the health care market, in particular the dental care market, does not operate as a perfectly competitive model. A variety of authors describe economic theories that address how the purchase of health care differs from the purchase of other goods and services $(18,51,101)$. Starr addresses the dependent position with which the patients interact with health care providers (101). Patients generally do not have complete information and often depend on the health care provider both to explain what is wrong with them and to suggest the appropriate cure. Frequently the patient is fearful, in pain, and ignorant of treatment options. Jeffers, Bognanno, and Bartlett attribute the majority of the gap between need and demand to consumer "ignorance" of what constitutes good health (102). These situations preclude rational economic decision making and violate the basic tenets of a competitive market. As a result, the amount of health care consumed by the patient is largely determined by suggestion of the provider.

Another important problem is the difficulty in obtaining reliable data (51). To date, no adequate system exists to collect and interpret the type of data required in econometric models for the private practice of dentistry. In determining the level of dental personnel supply, demand-based methods must depend on certain tenuous assumptions regarding future trends for both projections and econometrically generated forecasts (99). House comments that "the utilization rate was one critical variable in the estimation of future demand that appeared to be beyond the capability of existing data sources to 
resolve in a fully satisfactory manner" (13). Instead, questionable extrapolation and adjustment of national epidemiologic and expenditure survey data must be utilized. These models, therefore, cannot be used to estimate expenditures based on specific local services (103).

Demand-based methods of personnel assessment are also unable to evaluate need. They are incapable of estimating the type of personnel required to address existing disease levels, since demand-based models cannot assess changes in the health status of a population. Econometric models can specify visits, but will not be sensitive to changes in the quality or intensity of services delivered (103). In addition, these models often require complex computer programs and are difficult for most to understand. As such, they are not likely to be used outside of academic settings.

\section{"Factors that affect the demand for dental care are ... not well accounted for in the dentist-to-population ratio."}

A model based on a dental services market of current users also has the capability of perpetuating a health care system that, on the basis of its analysis, ignores changes that may influence new people to enter the system $(14,103)$. The demand for care is subject to many changes that may invalidate any but the most time-constrained predictions (15). Bailit lists demographics and the organization of health care systems as examples of the almost endless number of factors that can contribute to changes in effective demand (19).

Demographic changes represent a powerful force for change in the provision of health care. The aging of the population in the US, along with improvements in the economic conditions of the elderly, will not only result in changes in the types of services demanded, but in the construction of powerful constituencies capable of influencing national health policy (16). Changes in Medicare and Medicaid coverage or the implementation of comprehensive national health insurance also could provide quite a boost to effective demand (73). In addition, the creation of new technologies as well as temporal changes in the mix and quantity of services advocated by providers to consumers have the potential to create new or different demands. A demand-based model may not be useful in health care planning if it is incapable of recognizing and evaluating the effects of change in consumer- and provider-generated demand, as well as attending to the oral health care needs of a population (14).

Outcome. The Bureau of Health Professions' Econometric Model of the Dental Sector (EMODS) is nevertheless the fundamental method used by the federal government to forecast personnel requirements (78). The Bureau of Economic and Behavioral Research
(BEBR) of the ADA also uses an econometric model to generate dental personnel forecasts (79). Both bureaus, however, disagree with one another on the projections for dental personnel for the year 2000. The federal government predicts a shortage of dentists, whereas the ADA predicts a continued oversupply $(5,79,82,104)$.

The level of subjectivity and political influence within the personnel determination process is well illustrated by analyzing the crux of this argument. The government defines the "required number of dentists" to be the number of dentists required to prevent price inflation $(5,78)$. When the federal government states there will be a shortage of dentists, it is in reference to its desire to keep prices from rising disproportionately. But the ADA questions the relevance and use of a price ceiling in projecting dentist supply because it ignores future dental demand levels (5). The implication of the ADA's assertion is that demand will continue to lag behind the projected increased dentist supply and prices for service will become or remain low. As documented earlier, this assessment does not seem to be supported by fact.

Health economic theory is a relatively recent and untested discipline $(28,93)$. As a result, there has been little time to derive or validate its theories empirically. Because there is evidence that the dental care sector behaves economically in ways that differ significantly from other market systems, it may not be appropriate to rely so strongly on models from other sectors of the economy.

\section{Need-based Studies}

A need-based method considers the notion of professionally determined need for dental services in a population. Need-based studies find much utility within health services systems such as the National Health Service of Great Britain, and the Veterans Administration and Indian Health Service in the United States. These organizations address both need and demand in users and nonusers of the health care marketplace (2). Jeffers et al. (102) provide an economic orientation that differentiates need from demand. Need is not affected by a change in price and therefore is not dependent upon a price-related market of supply and demand. A "market shortage" of medical services relates specifically to the excess demand of those individuals currently within the medical market. In contrast, "normative shortage" is defined as the "quantity of medical services needed that exceeds the quantity of medical services demanded at existing prices" (102). The alleviation of a normative shortage will require active intervention by the market by altering supply or demand or both. This approach has been undertaken through various government programs suited for this purpose $(59,61,105)$.

Need-based studies use epidemiologic techniques both to measure oral disease levels and to identify the corresponding dental treatment needs within a population. Spencer states that reliable clinical information on 
disease status in a population is a key element in planning dental services (11). Need-based studies are also used for personnel estimation. One of the more ambitious projects in need-based personnel determination and collection of epidemiologic data concerning the dental care system was the North Carolina Dental Manpower Project (106).

Schoenfeld describes four steps in the estimation of personnel requirements from health-needs-based studies (107). These are: (a) assessment of the dental health status of a population, (b) translation of dental conditions into need for services, (c) estimation of the time required to provide the needed services, and (d) conversion of required time into estimate of personnel needed.

Using specified criteria, the conversion of oral health status findings to treatment needs is accomplished either at the time of the oral examination or afterwards (108). A direct assessment permits the examiner to consider many subjective aspects of the patient while still in his or her presence. Direct assessment of treatment needs was used in both the National Health and Nutritional Examination Survey I (NHANES I) and the North Carolina survey (106).

The process of treatment needs determination during an epidemiologic survey is divided into two distinct techniques. The first technique uses randomized subjects with calibrated examiners, while the second uses both randomized subjects and randomized, noncalibrated examiners. The benefits of using calibrated examiners is that the measures are relatively consistent and uniform. This technique is valuable in assessing secular disease trends, particularly when widely different geographic locales are being compared.

When the desired outcome is to measure the actual treatment likely to be rendered in a specific locale, then randomized subjects and uncalibrated, randomized examiners may be used. The result of this type of study has been called an estimate of "effective need" (Arthur JS, personal communication, Naval Dental Research Institute, Great Lakes, IL). Here, randomly selected subjects are matched with their primary dental care provider. The provider is then instructed to generate an oral health assessment and treatment plan for that subject. Because the assessment is done by the provider who will ultimately suggest treatment to the subject, it is likely to be highly aligned with the treatment that will be received by that subject. At the loss of repeatability, a more realistic assessment of the care provided within a population is thought to be obtained. One drawback with this type of study design is deciding how to allocate subjects who have no primary provider.

Indirect calculations of treatment needs can be accomplished after completion of an oral health status examination. These provide for a more flexible estimate in light of secular changes in technology or philosophy of care. Indirect calculations by necessity provide for the conservation of oral health status data. The conversion of health status to treatment needs is usually based on predetermined criteria that are uniformly applied to all subjects. Burt compared findings at a baseline survey of children in an incremental care program with the treatment actually received in the first year (109). This comparison provided the information needed to convert caries status into treatment needs.

Treatment needs may also be assessed indirectly through local or national surveys of private practitioners' patient records. Dental treatment records can provide valuable insight into past treatment patterns and behavior. The lack of standardization in both treatment planning and data recording, however, may invalidate comparisons and estimates emanating from these records. In addition, Bader et al. warned of the dangers of using national surveys of patients' records in the estimation of local or regional needs (110). They suggested that examiners be standardized.

The indirect estimation of treatment needs has been attempted by directly polling dental providers for their opinions on personnel requirements. Members of the Minnesota Dental Association were surveyed to ascertain which variables they considered to be important in the determination of needed personnel $(111,112)$. The most important factor affecting the ability of a locality to support a dentist was identified as the "dental IQ" of the population, an indication of demand rather than need. They concluded that dentists' opinions can be reliable estimates in identifying areas of true shortage. The selfinterest concerns and limited perspective of private practitioners, however, might generate a rather conservative estimate of personnel needs. Past disagreements between the federal government and local dental interests over the designation of personnel shortage areas substantiate the concern over this survey method (60).

A similar study was conducted by the American Association of Orthodontists (21). The membership was polled on their perception of "busyness," and this perception was related to the changing demographics of 12-year-old children in an attempt to predict future need for orthodontic care (21). A group that, in this way, limits its view of the population it serves will undoubtedly have better estimates of future personnel needs than groups that consider the entire population.

Regardless of the market forces at work, understanding the dental care needs of a population is critical if successful programs are to be designed to improve health status. From a public health standpoint, a healthneeds approach to estimating personnel may be preferable to other techniques because it identifies not only disease levels, but also permits treatment to be prioritized and allows evaluators to track movement toward health objectives (107). Needs-based planning can be successful in certain dental programs where the focus of planners is limited to a well-defined target 
population. Only by using needs assessments can explicit health goals be developed and requisite personnel levels be determined. The ability to conduct meaningful needs assessments is rare in the private dental sector in the United States. Many government programs with welldefined patient populations may be successful in conducting an accurate needs assessment on a local basis. For example, on an American Indian reservation or a military base, it may be realistic to survey the population and make need-based estimates of personnel requirements. The concern in these cases is not with the production and migration of dental personnel, but rather with matching the effective demand with a well-controlled supply of dental personnel.

The concept of need in projection of adequate personnel supply should not be ignored within any health system. Because of the strong positive relation between socioeconomic status (SES), dental care-seeking behavior, and access to dental care, demand for dental services is often lowest among those individuals with the highest needs $(7,9,113-116)$. Barriers confronting those who are unable effectively to demand dental care include both enabling and predisposing factors that are affected by economic, social, and cultural vectors. This inverse relationship between demand and dental need was highlighted by the National Preventive Dentistry Demonstration Project, where over half of the total caries experience occurred in 20 percent of the individuals studied (7). A majority of these affected individuals were of a low socioeconomic background. Reliance on demand-based studies would result in a failure to plan for the care of many low SES groups. To prevent excluding these special population groups, the decision to target need and improve access to dental care remains a critical personnel planning issue.

Disadvantages. Although the epidemiologic survey is of value in health-based resource planning, it must be used with caution when considering a demand-based economic system. Reinhardt rightly criticizes need-based studies as potentially unrealistic in their ability to predict personnel needs in the private sector (92). These systems provide poor estimates of resource needs because they fail to predict the opinions of future experts of normative need and the changes in the provision and financing of care. It is effective demand and not needs or wants that drives the system. In failing to consider consumer demand for dental services, epidemiologic surveys that estimate normative needs alone will be imperfect in predicting the ultimate care consumed (92).

Nuttall and Elderton demonstrated how dental epidemiologic data can fail to predict adequately the actual consumption of resources on a national level (117). The problem resulting from the use of such data is that the correlation between needs estimated and care delivered becomes a function of the incidence of disease. Prevalence data are frequently translated into future dis- ease incidence and then converted into future treatment needs. Certain precarious assumptions concerning future changes in oral disease patterns - as well as the economic, social, and political climate that affect utilization of dental care-must then be made.

Burt acknowledged the need for incidence data (caries increments) when trying to calculate the personnel required to meet the restorative needs in children (109). He estimated the incidence rate by extrapolation from national cross-sectional studies and clinical trials. Inaccuracies in this technique may be magnified over time when underlying secular changes occur. Unfortunately, obtaining direct estimates of oral disease incidence rates is often preclusively expensive or logistically improbable.

The North Carolina Dental Manpower Project attempted to determine oral health status of the population, as well as demand for care and dental personnel productivity (106). Once again though, the effort to determine personnel needs directly was limited by use of prevalence data. It is difficult to predict required supply levels when the level of services that will be consumed cannot be forecast $(120,121)$.

As a result of the North Carolina study, the relation between rough field data and ideal clinical data was examined by Long, Rozier, and Bawden (122). They compared the difference in the caries detected in a "survey" with what was called the "true" caries level found during an examination in an ideal clinical setting. By regressing the data, they estimated that the survey underestimated by 7 percent the number of decayed primary and permanent teeth.

The estimation of treatment needs at the time of examination contains some significant drawbacks. Although estimations made at the time of the examination may help examiners feel they are making the "right" decision, interexaminer reliability (consistency) frequently is lost. One telling example noted by Elderton and others was the wide variability found between the diagnosis of caries and the restorative treatment ultimately received by British Health Service patients $(123,124)$.

Complete edentulism is perhaps the easiest oral condition to diagnose and to translate into treatment needs with reliability and validity (125). Yet with recent advancements in implant technology, the range of treatment options has expanded. When compared to the subsequent treatment actually provided, prosthodontic needs have been shown to be overestimated by epidemiologic surveys (125). What often causes confusion in studies of prosthodontic treatment needs is determining what types of providers will render the service. Will denturists be providing services, and should dental laboratory personnel be included? With continued pressure to expand the roles of assistants and hygienists, some portion of the work associated with 
denture production is shifted to nondentists. These factors will confound any production function based solely on estimates of the dentists' time.

When diseases as difficult to define and measure as periodontal disease and malocclusion are considered, the job of deciding treatment needs becomes much harder $(120,126,127)$. As can be seen by the present uncertainty with respect to the progression and treatment of periodontal disease, the notion of the nature and treatment of a disease can change over time $(128,129)$. Nuttall and Elderton concluded that while dentists show a strong predilection for restorative care, even in the absence of caries, there exists a high level of disagreement on what constitutes appropriate treatment for any given diagnosis (117).

Further complicating the utility of a needs-based method is the question of physical, economic, and attitudinal barriers that preclude conversion of need to effective demand. Such determinants have been advanced as a reason why approximately 50 percent of Americans had one or more dental visits during a oneyear period (130). The relatively recent advent of dental insurance coverage has not resulted in a significant increase in the overall utilization of dental services $(9,19,73$ $75,114)$. Having been demonstrated to have a positive effect on oral health status (75), demand for dental services under insurance coverage probably increases only among those populations who would seek or had been seeking care anyway (113,131-133). A thorough understanding of the various cultural and behavioral barriers that block access to the dental care system is therefore essential in determining an adequate supply of personnel based on need. When combined with the problems of converting available data into predictors of treatment needs, personnel estimates must be made with caution $(73,122)$.

\section{Discussion}

On the national and state levels, personnel policy planners have the responsibility of affecting the supply and the distribution of personnel. As can be seen from the federal policy initiatives of the last four decades, national efforts to change personnel levels are slow. Furthermore, simply planning to increase the number of providers will in no way guarantee that they will meet the need for care (134). Bloom and Peterson, in a study of physician personnel expansionism, concluded that simply increasing the number of physicians only suits the needs of academic training programs and does not improve the health of the population (135). Reinhardt found that increasing overall physician productivity nationally by 4 percent would provide more medical services to the public than would be added by the annual graduating class of physicians in all US medical schools (136). Perhaps the easiest and quickest way to meet the present unmet need in certain populations would be to provide new economic incentives to existing practitioners, rather than to produce new providers.

From a public health perspective, the goal for personnel planners, should be not only to plan efficiently for the production of providers, but also to ensure their distribution in a way that reflects the underlying needs of the population. That distribution would ideally be a function of comprehensive and explicitly stated health goals for the population derived from need. Establishing need in the population and determining health goals is a process in which there is little consensus. The problem then becomes aligning need with demand and relating that to personnel production. The present method of financing care in the United States means that population need frequently takes a back seat to effective demand. The prevailing political sentiment in the United States affirms a demand-based system where access to health care is the responsibility of the individual and directly proportional to the individual's ability to pay for the service. Dunning offers a sensitive commentary on the ongoing economic polarization in the United States (137). A costly twotiered system of health care has evolved in the United States. Growing numbers of the poor are increasingly unable to obtain needed medical and dental care, while the swelling numbers of health providers concentrate their treatment and marketing energies in the wealthy portion of the population.

It is also difficult to address problems in the distribution of dentists with personnel planning based at the national level. The absence of objective and centrally directed personnel planning, called the genius of the American educational system by Bailit, means that any information made available from personnel planning models will find limited use in any type of direct planning for health care on a national basis (19). Considering the problems inherent in all planning methods, however, the ability of personnel models to provide recommendations in any but the most general terms is doubtful. Reliance upon the dentist-to-population ratio has resulted in an inadequate assessment of the distribution of dental personnel $(29,30)$. Maldistribution was a concern of personnel planning research when there was thought to be an inadequate supply of dentists to meet the oral health needs of the population. An implication of the current perception of a dentist oversupply as predicated by the dentist-to-population ratio is that maldistribution will somehow correct itself. This attitude has contributed to the virtual elimination of all National Health Service Corps (NHSC) dental trainees and scholarships despite 785 dental health personnel shortage areas that are still designated by the same dentist-to-population ratio (78).

Personnel planning at the state and local level can be more efficient. Where a well-defined, homogeneous population exists, demand is easier to estimate and planners can be concerned with matching the supply of dental 
services with effective demand. As a result, a demandweighted epidemiologic assessment of need can be an effective planning strategy.

Planning at the state, county, city, or facility level has the ability to overcome many of the problems encountered in planning on a national level. The coordination, analysis, and monitoring of the activities at this level mandate the need for viable state and local dental programs.

Working against efficient planning at the state and local levels are the various perceptions held by organized dentistry, the federal and state governments, and the dental education community, that supply levels are inappropriate. These perceptions are all too frequently based on anecdotal information or the use of an inadequate planning model. The result is often ill-conceived policy resulting in an economic paradox where prices for dental service rise when supply levels deviate either to the high or low side of some ideal. Reactionary policy often contributes to further restraints on where and how care is delivered (138). Organized dentistry lobbies for more restrictive state practice acts as the perception of an oversupply increases among a state's dentists. Stricter regulations create barriers to the entry and efficient utilization of dental personnel, increasing the cost of services and decreasing access, especially to needy populations. Typically, government's response to increasing prices and decreasing access is to encourage increases in supply levels. Dental providers then, fearing loss of income from increased competition, increase prices or recommend marginally needed procedures to their patients (139).

Given the current state of the art, the objective determination of appropriate supply levels may border on the impossible. Rather than working against increased government involvement in the profession, however, organized dentistry should perhaps encourage greater involvement with state and federal agencies so that rational planning could eventually be developed. All future planning will only be as effective as the quality of the data on which it is based. Accurate accounting of the productive capacity of providers and the needs of consumers will help to make planning more effective, but can only be accomplished jointly through governmental and professional cooperation.

The ability to predict personnel requirements depends on how well a chosen method objectively deals with changes in demand, need, and supply. Need changes slowly as it follows secular trends in disease, diagnosis, and treatment. The number of dentists also changes slowly because the number of individuals already in the educational pipeline should cause future supply levels to remain relatively constant for the next decade. Demand has the potential for more rapid change. Revolutionary technological developments such as a caries vaccine could serve to change demand rapidly. The institution of a universal dental health insurance program could also increase demand levels immediately and significantly.

Although national dental personnel policy per se cannot be expected to resolve these problems, it can still be part of an overall approach that attempts to overcome barriers that preclude the translation of need into demand. One step that could be taken toward the alignment of need with demand would be to enact federal legislation to establish a well-planned and closely monitored universal health insurance program that includes comprehensive coverage for dental care (140). A recent household interview survey conducted by the National Center of Heal th Statistics found that regardless of income level, insurance coverage was positively associated with the use of dental services (9). Appropriate health-oriented planning could then be conducted to identify secular trends and priority treatment needs in subsectors of the population. If the underfunded and piecemeal approach the federal government adopted toward dental programs in Medicaid can be avoided, the national health insurance with comprehensive dental coverage has the potential to increase demand in populations of greatest need.

\section{Conclusions}

It has been shown that the information necessary to predict personnel requirements with confidence is generally unavailable. Each technique suffers from a lack of critical data and the inability to account for future epidemiologic, social, economic, and political change. Depending on who coordinates the planning activity, these techniques also generally lack objectivity. The absence of any central planning by the US government over health personnel production means that no model, regardless of its accuracy, will be able to provide direct input into the personnel production process. As a result, the predictive ability of each personnel method remains unclear.

One certainty is that planning for dental personnel production will continue regardless of the quality of the data or planning models available. It has been argued that any planning is better than no planning, but problems may arise when more credence is given to the use of a planning model than its prognostic abilities merit. The consequences of any planning decision must be evaluated in terms of the cost in resource commitments and health outcomes that result from its implementation. These costs must then be weighed against the uncertainty of the information at hand.

Dentist-to-population ratios have served historically as the basis for health personnel planning because they are easy to understand and use. These ratios have been shown to be rather crude and of limited use in comprehensive health planning on a large scale. Their insensitivity to the complexities of factors important in health planning make them useful in only the most circumspect 
situations.

Demand-based methods attempt to identify and quantify market forces that affect consumers and suppliers and, thus, are of importance in health care delivery systems that affirm the role of supply and demand. However, demand-based methods measure only the current consumer market. They are insensitive to changes in disease levels and in identifying special populations in need. These models are presently hindered by the lack of reliable data, as well as their inability to account for unforeseen economic, political, technological, and demographic change.

National econometric models add a level of sophistication by examining the effects of change upon supply, demand, and price. The value of these models stems from their attempt to estimate future demand by identifying and incorporating various economic determinants of the health care marketplace. However, econometric models are based on rather far-ranging assumptions of the national economy. The vagaries of the economy are self-evident, and any theory that attempts to predict economic events will be as labile as the economy itself. The output of these models is usually couched in such generalities as to be almost useless for planning. Presently, econometric models may be of little more than academic interest.

Intuitively, need-based studies would seem to offer the best estimates of treatment needs and personnel requirements. These methods are able to address both users and nonusers of the health care marketplace. Their use of prevalence data, however, creates problems when attempting to predict future treatment needs. The level of supply resources is difficult to estimate when the level of services to be consumed cannot be predetermined. Demand weighting may be used to bring need-based study results more in line with the amount of care that will ultimately be dispensed. In certain limited situations, epidemiologic studies of dental needs coupled with predictable demand estimates may yield a reasonable estimate of the personnel needed to reach explicit health objectives. To meet these objectives, however, the reduction of barriers to the dental care system should parallel this activity.

The present perception of an oversupply continues to have dire policy ramifications regarding dental education, dental personnel shortage areas, special populations in need, and the funding of federal, state, and local dental public health programs. Once programs become structurally and philosophically defunct, the chance of their reappearance is negligible. All of these planning models, with the exception of the dentist-to-population ratio, have the potential to provide valuable planning information. What is needed is continuing health services and epidemiologic research, so that better quality information can be obtained that will lead to improved personnel planning decisions.

\section{Acknowledgments}

The authors would like to express their appreciation to Dr. David Striffler and Dr. Linda Niessen for their thoughtful comments during the preparation of this manuscript.

\section{References}

1. Arnljot HA, Barmes DE, Cohen LK, Hunter PBV, Ship II. Oral health care systems: an international collaborative study. World Health Organization. London: Quintessence Publishing 1985.

2. DeFriese GH, Barker BD. Assessing dental manpower requirements: alternative approaches for state and local planning. Cambridge, MA: Ballinger Publishing, 1982.

3. American Dental Association. FTC to probe ADA advertising standards: Association vows to back code as public benefit. ADA News 1988 Feb 8;19:1,10,11.

4. American Dental Association, House of Delegates. (Resolution 58H-1986.) Am Dent A Trans 1986;127:515.

5. American Dental Association. Dentist supply numbers computed: ADA disagrees with government's projection. ADA News 1985 Apr 1;16:10-12.

6. Burt BA. The future of the caries decline. J Public Health Dent 1985 Fall;45:261-9.

7. Bell RM, Klein SP, Bohannan HM, Graves RC, Disney JA. Results of baseline dental exams in the National Preventive Dentistry Demonstration Program. Santa Monica, CA: Rand R-2862-RWJ, 1982.

8. Beck JD, Hunt RJ. Oral health status in the United States: problems of special patients. J Dent Educ 1985;49(6):407-25.

9. Kouar MG, Jack S, Bloom B. Dental care and dental health: NHIS. Am J Public Health 1988 Nov;78:1496-7.

10. Freeman HE, Blendon RJ, Aiken LH, Sudman S, Mullinix CF, Corey CR. Americans report on their access to health care. Health Aff 1987 Spring 6:6-18.

11. Spencer AJ. The estimation of need for dental care. J Public Health Dent 1980 Fall;40(4):311-27.

12. Striffler DF. Dental treatment need, demand, and utilization. In: Striffler DF, Young WO, Burt BA. Dentistry, dental practice, and the community. 3rd ed. Philadelphia: WB Saunders, 1983:293-339.

13. House RK. Estimating future dental care requirements: the implications for dental manpower. Can Dent Assoc J 1987 Feb;53:99-105.

14. Odrich J. Dental manpower planning: can we ever get it right? J Public Health Policy 1985 Dec;6:539-52.

15. Cole RB, Cohen LK. Dental manpower: estimating resources and requirements. Milbank Mem Fund Q 1971 Mar;49:29-62.

16. Gambucci JR, Martens LV, Meskin LH, Davidson GB. Dental care utilization patterns of older adults. Gerodontics 1986 Feb;2:11-15.

17. Feldstein PJ, Roehrig CS. A national econometric forecasting model of the dental sector. Health Serv Res 1980 Winter,15:415-27.

18. Yule B, Parkin D. The demand for dental care: an assessment. Soc Sci Med 1985 Jul;21:753-60.

19. Bailit HL. Environmental issues in dentistry: reflections on the practice of dentistry in the 21st century. Gerodontics 1987 Oct;3:18492.

20. Bane F. Dentists for a growing America. In: Physicians for a growing America. Report of the Surgeon General's consultant group on medical education. Appendix A. Washington, DC: Government Printing Office, 1959.

21. American Association of Orthodontists. The AAO study of the availability of orthodontic services. Am J Orthod 1975 Sept;68:32632.

22. American Dental Association. Growth in population and number of dentists to 1985. J Am Dent Assoc 1973 Oct;87:901-4.

23. American Dental Association. Numbers of graduated required in future years. J Am Dent Assoc 1956 Apr;52:484-8.

24. American Dental Association. Changes in the distribution of dentists during 1954-56. J Am Dent Assoc 1958 Jan;56:105-9.

25. American College of Dentists. Proceedings of a workshop on dental manpower needs in the 1970s. J Am Coll Dent 1968 Apr;35:97-237.

26. Smith QM. The growing shortage of dentists in the United States. Am J Public Health 1958 Jan;48:38-45.

27. Lee RC. Designation of health manpower shortage areas for use by Public Health Service programs. Public Health Rep 1979 JanFeb;94:48-59.

28. Born DO. Dental manpower planning and distribution: a survey of the literature. In: American Dental Association. Advanced in socio- 
dental research. Vol 2. Chicago, IL: American Dental Association, 1975:v-xxvi.

29. Waldman HB, Shaprin ML, Pollack BR. The maldistribution of dentists. NY J Dent 1979 May;49:141-52.

30. Meskin LH, Martens LV. Commentary on dental manpower: the dentist-to-population ratio. J Public Health Dent 1970Spring:30:958.

31. Barron EG, Shirley WL, Waldrep AC A realistic approach to locating dental practices. J Am Dent Assoc 1984 Dec;109:903-8.

32. Henderson WG. The identification of dental shortage and surplus areas in Iowa. Am J Public Health 1974 Jan;66:70-2.

33. Willcocks AJ, Richards ND. Dental manpower and dentistry as an institution. In: Richards ND, Cohen LK. Social sciences and dentistry: a critical bibliography. Fédération Dentaire Internationale. The Hague, Netheriands: A. Sijthoff, 1971:120-49.

34. House RK, Johnson GC, Edwards FA. Manpower supply study scenarios for the future: dental manpower to 2001. Can Dent Assoc J 1983 Feb;49:85-98.

35. American Dental Association. Expenditures and prices for dental and other health care. J Am Dent Assoc 1959 Dec;59:1183-9.

36. American Dental Association. Number of dental graduates required annually to 1985. J Am Dent Assoc 1965 Sept;71:694-8.

37. American Dental Association. Population per dentist 1960-1980. J Am Dent Assoc 1962 May;64:700-6.

38. Amercan Dental Association, House of Delegates (Resolution 77H1984). Am Dent A Trans 1984;125:537-38.

39. US Bureau of the Census. Historical statistics of the United States: colonial time to 1957. Washington, DC: Government Printing Office, 1960.

40. Gies WJ. Dental education in the United States and Canada. New York: The Carnegie Foundation for the Advancement of Teaching, 1926.

41. American Dental Association. Distribution of dentists in the United States by state, region, district, and county, 1970. Bureau of Economic Research and Statistics. Chicago, IL: ADA, 1971.

42. Lee RI, Jones LW. The fundamentals of good medical care. Chicago: University of Chicago Press, 1933.

43. President's Commission on the Health Needs of the Nation. Building America's health. Washington, DC: Government Printing Office, 1953.

44. Moen BD. Realism in maintaining the present population ratio in the next seventeen years. J Am Coll Dent 1959 Jun;26:146-8.

45. The Survey of Dentistry. In: Hollinshead BS. Commission on the Survey of Dentistry in the United States. Appendix A. Washington, DC: American Council on Education, 1961:475-82.

46. Future requirements of dental manpower and the training and utilization of auxiliary personnel. Proceedings of the workshops at the University of Michigan. W.K. Kellogg Foundation Institute. Ann Arbor, MI: Edwards Bros, 1962.

47. USNational Center for Health Statistics. Current estimates from the National Health Interview Survey. DHHS pub no (PHS) 87-1592. Series 10, no 164, Hyattsville, MD, 1987.

48. American Dental Association. Association testifies in support of Health Educational Assistance Act. J Am Dent Assoc 1963 Mar; 66:389-91.

49. United States Department of Health, Education, and Welfare. Health Professions Education Assistance Program: Report to the President and the Congress. Washington, DC: Government Printing Office, 1970.

50. Burt BA. Dental personnel in the United States. In: Striffler DF, Young WO, Burt BA. Dentistry, dental practice, and the $\infty \mathrm{m}$ munity. 3rd ed. Philadelphia: WB Saunders, 1983:421-65.

51. Feldstein PJ. Financing dental care: an econometric analysis. Lexington, MA: DC Heath, 1973.

52. US Public Health Service, Division of Allied Health Manpower. The Allied Health Professions Personnel Training Act of 1966: Report to the President and the Congress. DHHS, Washington, DC: Government Printing Office, 1970.

53. Whiteside DF. Dentists practicing in designated areas of shortage in health personnel. J Public Health Dent 1974 Summer;34:195-8.

54. United States Statutes at Large. Comprehensive Health Manpower Training Act of 1971. Public Law 92-157, Nov. 18, 1971. 92nd Congress:85:431-63.

55. Feldstein PJ. A preliminary evaluation of federal dental manpower subsidy programs. Inquiry 1974 Sept;11:196-204.

56. American Dental Association, House of Delegates. (Resolutions 169H-1976, 170H-1976, 171H-1976, 172H-1976, 173H-1976). Am
Dent A Trans 1976;117:910-12.

57. Albertini TF, Hillsman JT, Crawford BL. Federal financing of dental services. J Dent Educ 1984 Nov;48:606-18.

58. Redman E. The dance of legislation. New York: Simon and Schuster, 1973.

59. Mullan FSM. TheNational Health Service Corps. Public Heal th Rep 1979 Jul-Aug;94(Spec Iss):2-6

60. American Dental Association. House of Delegates Statement on National Health Service Corps (Resolution 6H-1976). Am Dent A Trans 1976;117:849-50.

61. American Dental Association, House of Delegates. (Resolution 71-1972-H). Am Dent A Trans 1972;113:696-7.

62. American Dental Association, House of Delegates. (Resolution 62-1974-H). Am Dent A Trans 1974;115:692-3.

63. Kaplan RI. Are we producing too many dentists? J Am Coll Dent 1977 Jan;44:15-16.

64. American Dental Association. House of Delegates (Resolution 50 1975-H). Am Dent A Trans 1975;116:701-2.

65. American Association of Dental Schools. Executive committee report to the House of Delegates: proceedings of the 56th annual session. J Dent Educ 1979 Jul;43(7):384-402.

66. American Dental Association, Council on Dental Education. Special report on dental auxiliary utilization and education. Am Dent A Trans 1976;117:208-42.

67. Whiteside DF. Explanation and interpretation of the Heal th Profes sions Educational Assistance Act of 1976. J Dent Educ 1977 Aug;41:479-82.

68. American Association of Dental Schools. Six dental schools reject capitation. Bull Dent Educ 1978 Oct;11:1-2.

69. Health manpower shortage areas. Appendix B: criteria for designation of areas having shortages of dental manpower. Federal Register 1980 Nov 17;45(23):760003-5.

70. Lave JR, Lave LB, Leinhardt S. Medical manpower models: need, demand, and supply. Inquiry 1975 Jun;12:97-125.

71. Shanley DB, Hobdell $\mathrm{MH}$. Estimating oral health manpower requirements. J Irish Dent Assoc 1983 Nov-Dec;29:81-3,99.

72. American Dental Association. An analysis of dental practice from 1952 to 1976. Council on Dental Practice and Bureau of Economic and Behavioral Research. J Am Dent Assoc 1980 Jan;100:89-96.

73. United States Division of Health Care Services. Report of a study: public policy options for better dental health. Institute of Medicine. Washington, DC: National Academy Press, 1980.

74. Sonkin S. Financing dental care for older Americans in the 21st century. Gerodontics 1985 Dec;1:291-3.

75. Bailit H, Newhouse J, Brook R, Duan N, Goldberg G, Hanley J, Kamberg C, Spolsky V, Black A, Lohn K. Does more generous dental insurance coverage improve oral health? J Am Dent Assoc 1985 May;110:701-7.

76. US National Center for Health Statistics. Dental Manpwer 1965-67. Lotzkar S, Johnson DW. DHEW pub no (PHS) 1000, Series 14, no 1. Hyattsville, MD, 1968.

77. Birch S. Equity and efficiency in medical manpower planning: defining objectives and looking toward the future. Health Policy 1985;4:341-6.

78. Health Resources and Services Administration, Bureau of Health Professions. Fifth report to the President and Congress on the status of health personnel in the United States. Chapter 5. DHHS (PHS), Washington, DC: Government Printing Office, 1986.

79. Perich ML. American Dental Association manpower projections. J Dent Educ 1987 May;51:219-23.

80. American Dental Assoclation, Bureau of Economic and Behavioral Research. Reports of councils, bureaus, and other association agencies. Am Dent Assoc Annual Rep Resolutions 1988;129:59-68.

81. American Association of Dental Schools. Policy statements: proceedings of the 65th annual session. J Dent Educ 1988 Jul;52(7):386-96.

82. American Dental Association. Supply of dentists has peaked, experts say: student enrollment down. ADA News 1988 Jul 4;19:1,1213.

83. Born DO. Auxiliary personnel. In: Kudrle RT, Meskin L. Reducing the cost of dental care. Minneapolis, MN: University of Minnesota Press, 1983:67-97.

84. American Dental Association, House of Delegates. (Resolution 6H-1987). Am Dent A Trans 1987;128:510.

85. American Dental Association. Thoughts on supply and demand. ADA News 1988 Apr 11;19:4.

86. American Dental Association. Dental incomes edge inflation, sur- 
veys show. ADA News 1988 Apr 11;19:1,7.

87. Sloan FA, Feldman R. Competition among physicians. In: Greenberg $W$, ed. Competition in the health care sector. Proceedings of a conference sponsored by the Bureau of Economics, Federal Trade Commission, Washington, DC, 1977:57-131.

88. Striffler DF. Dentist oversupply (?), dentistry, and dental public health. J Public Health Dent 1984 Summer;44(3):98-9.

89. Kuthy RA, Odom JG. Local dental programs: a descriptive assessment of funding and activities. I Public Health Dent 1988 Winter; 48(1):36-42.

90. Cavanaugh GD. Dental manpower in Minnesota, USA.J Jrish Dent Assoc 1983 Nov-Dec;29:92-3.

91. McDermott RE. Demand and supply of dental services: an economic perspective. Can Dent Assoc J 1986 Dec;52:993-6.

92. Reinhardt UE. The GMENAC forecast: an alternative view. Am J Public Health 1981 Oct; 71:1149-57.

93. Maruizi AR. Economic essays on the dental profession. Iowa City: University of Iowa, 1969.

94. American Dental Association, Task Force on National Health Programs. The requirements for dental and dental auxiliary manpower. Dentistry in national heal th programs: reports of the special committees. Chicago: American Dental Association, 1971.

95. Beck JD, McGill JT. Projecting shortages and surpluses of dentists from available data. J Public Heal th Dent 1976 Summer;36(3):17180.

96. American Dental Association. Dental planning information: more than a body count. J Am Dent Assoc 1978 May;96:776-80.

97. US Health Resources and Services Administration. Projections of national need for dentists: 1980, 1985, and 1990. Division of Dentistry. DHEW pub no (HRA) 78-70. Washington, DC: Government Printing Office, 1977.

98. US Department of Health, Education, and Welfare. Forecasts of employment in the dental sector to 1995. Division of Manpower Analysis. DHEW pub no (HRA) 79-6. Washington, DC: Government Printing Office, 1979.

99. Littleton PA. Dental manpower supply and requirements: the effect of national estimates on individual dental schools. J Dent Educ 1980 May;44:241-5.

100. Hirsch GB, Killingsworth WR. A new framework for projecting dental manpower requirements. Inquiry 1975 Jun;12:126-42.

101. Starr P. The social transformation of American medicine. New York: Basic Books, 1982.

102. Jeffers JR, Bognanno MF, Bartlett JC. On the demand versus need for medical services and the concept of "shortage." Am J Public Health 1971 Jan;61:46-63.

103. Gillings DB, Sollecito WA, Douglass CW. A need-based model to project national dental expenditures. J Public Health Dent 1983 Winter;43(1):8-25.

104. Solomon E. Manpower trends in the health professions: slower growth predicted for dental practitioners. J Dent Educ 1984 Oct;48:571-2.

105. Rosenblatt RA, Moscovice I. The National Health Service Corps: rapid growth and uncertain future. Milbank Mem Fund Q 1980 Spring:58:283-309.

106. Bawden JW, DeFriese GH. Planning for dental care on a statewide basis: the North Carolina Dental Manpower Project. Chapel Hill, NC: The Dental Foundation of North Carolina, 1981.

107. Schoenfeld WH. Estimating dental treatment needs from epidemiological data. J Public Health Dent 1981 Winter;41(1):25-32.

108. Beck JD, Luebke NH. An index of treatment needs for population groups: a pilot study. J Public Health Dent 1978 Summer;38(1):21222.

109. Burt BA. Diagnostic and preventive services in an incremental dental plan for children. J Public Heal th Dent 1977 Winter;37(1):3146.

110. Bader JD, Mullins MR, Webster DB. Aspects of planning and evaluation of children's dental care in Appalachia. I Public Health Dent 1979 Winter;39:(1)27-34.

111. Born DO. Dental manpower research in Minnesota. Northwest Dent 1974 Mar-Apr;53:96-101.

112. Tielde IW, Born DO. The dental manpower shortage area study in Minnesota. Northwest Dent 1975 Jul-Aug;54:174-8.

113. Douglass $C W$, Cole $K O$. Utilization of dental services in the United States. J Dent Educ 1979 Apr;43:223-38.

114. Conrad DA, Grembowski D, Milgrom P. Dental care demand: insurance effects and plan design. Health Serv Res 1987 Aug;22:341. 67.
115. Weintraub JA, Burt BA. Oral health status in the United States: tooth loss and edentulism. J Dent Educ 1985 Jun;49:368-76.

116. USNational Institute for Dental Research. The prevalence of dental caries in United States children, 1979-1980: The National Dental Caries Prevalence Survey, DHHS pub no (NIH)82-2245, Washington, DC: Government Printing Office, 1981.

117. Nuttall NM, Elderton RJ. The nature of restorative dental treatment decisions. Brit Dent J 1983 Jun;154:363-5.

118. White RP, Bawden JW. Conceptual development and organization of the North Carolina Research Studies. J Public Health Dent 1981 Winter;41(1):60-3.

119. DeFriese GH, Konrad TR. Estimating dental manpower requirements on a statewide basis. J Public Health Dent 1981 Winter; 41(1):33-40.

120. Nuttall NM. Capability of a national epidemiological survey to predict general dental service treatment. Community Dent Oral Epidemiol 1983 Nov;11:296-301.

121. Spencer AJ. The role of epidemiological surveys in planning dental services: are they useful? Community Dent Health 1985 Dec;2:27783.

122. Long LM, Rozier RG, Bawden JW. Estimation of actual caries prevalence and treatment needs from field survey caries information on a child population inthe USA. Community Dent Oral Epid 1979 Dec;7:322-9.

123. Elderton RJ. Implications of recent dental health services research on the future of operative dentistry. J Public Health Dent 1985 Spring;45(2):101-5.

124. Pickles TH. The relationship of caries prevalence data and diagnosed treatment needs in a child population. Med Care $1970 \mathrm{Nov}$ Dec;8:463-73.

125. EddieS, Elderton RJ. Comparison of dental status determination in an epidemiological survey with prosthetic treatment recived. Community Dent Oral Epidemiol 1983 Oct;11:271-7.

126. Davies GN, Horowitz HS, Wada W. The assessment of dental caries for public health purposes. Community Dent Oral Epidemiol 1973;1:68-73.

127. Douglass CW, Sollecito W, Gammon M, Rundle DG, Gillings DB. Estimating the market for periodontal services in the United States. J Am Dent Assoc 1984 Jun;108:968-72.

128. Socransky SS, Haffajee AD, Goodson JM, Lindhe J. New concepts of destructive periodontal disease. J Clin Periodontol 1984 Nov;11:21-32.

129. Cohen ME, Ralls SA. False positive rates in the determination of changes in probing depth-related periodontal measurements. J Periodont Res 1988 May;23:161-5.

130. USNational Center for Health Statistics. Dental visits, volume, and interval since last visit: United States 1978-1979. DHHS pub no (PHS) 82-1566, Series 10, no 138, Hyattsville, MD, 1982.

131. Lewis DW. Dental manpower, supply, and demand projections and changing demography and dental disease. Can Dent Assoc J 1986 Jan;52:33-40.

132. Davies AR, Bailit HL, Holtby S. Oral health status in the United States: will improved health lead to decreased demand for dental services? J Dent Educ 1985 Jun;49:427-31.

133. US Department of Health, Education and Welfare. Possible directions for future research. In: Factors which affect the utilization of dental services. DHEW pub no(HRA) 64-78, Hyattsville, MD, 1978.

134. Fahs IJ, Choi T, Berches K, Zakanasen P. Indicators of need for health care personnel: the concept of need. Med Care 1971 MarApr;9:144-52.

135. Bloom BS, Peterson OL. Physician manpower expansionism: a policy review. Ann Int Med 1979 Feb;90:249-56.

136. Reinhardt UE. A production function for physician services. Rev Econ Stat 1972 Feb;54:55-66.

137. Dunning JM. The best is the enemy of the good.JPublic Health Dent 1988 Winter;48(1):3-4.

138. Collins W. Conflicting interests of state boards and the public welfare. J Dent Educ 1985;49(11):743-5.

139. Grembowski $D$, Milgrom $P$. The influence of dentist supply on the relationship between fluoridation and restorative care among children. Med Care 1988 Sept;26:907-17.

140. Anderson R, Newman J. Societal and individual determinants of medical care utilization. Milbank Mem Fund Q 1973;51:95-124. 